\title{
PEG-based Laxative NER1006
}

National Cancer Institute

\section{Source}

National Cancer Institute. PEG-based Laxative NER1006. NCI Thesaurus. Code C103299.

A preparation containing the nonabsorbable polymer polyethylene glycol (PEG or macrogol) 3350 with laxative activity. Upon oral administration, the PEG-3350-based laxative NER1006 promotes the retention of water in the bowel. This increases both the water content and volume of stool, which results in increased gastrointestinal motility and the evacuation of colonic contents leading to a complete cleansing of the colon. Compared to the 4 liter PEG-3350-based preparations, this PEG-based laxative is a low volume (2 liter) preparation, which may improve tolerance. 